\title{
An enzyme immunoassay for detecting Cryptosporidium in faecal and environmental samples
}

\author{
P. A. CHAPMAN, BARBARA A. RUSH and J. MCLAUCHLIN*
}

\begin{abstract}
Public Health Laboratory, Northern General Hospital, Herries Road, Sheffield S5 7AU and *Division of Microbiological Reagents and Quality Control, Central Public Health Laboratory, 61 Colindale Avenue, London NW9 5 HT
\end{abstract}

\begin{abstract}
Summary. An enzyme immunoassay (EIA) with a monoclonal antibody to cryptosporidium oocysts was developed and evaluated for the examination of faecal and environmental samples. The EIA was as sensitive as microscopy for detecting Cryptosporidium but also produced some positive results which could not be confirmed by a modified Ziehl-Neelsen technique or by immunofluorescence microscopy. These specimens reacted also with heterologous antibodies in EIA, suggesting false positive results.
\end{abstract}

\section{Introduction}

Cryptosporidium is now recognised worldwide as an important intestinal pathogen causing diarrhoeal disease in man and animals. ${ }^{1}$ The source of infection for man is diverse. Infections in domestic and farm animals are common ${ }^{2-4}$ and infection of man may result from contact with infected animals or ingestion of contaminated food..$^{5-7}$ Person-toperson transmission of Cryptosporidium may also occur, ${ }^{8-11}$ and possible outbreaks of cryptosporidiosis associated with contaminated drinking water supplies ${ }^{12-15}$ and a municipal swimming pool have been a recent cause for concern to public health authorities. Microscopic confirmation of the presence of Cryptosporidium in water samples is laborious and costly. ${ }^{16}$ The aim of this study was to develop an enzyme immunoassay (EIA) based on monoclonal antibody (MAb) to cryptosporidium oocysts, and to compare this with conventional methods of detecting Cryptosporidium by microscopy.

\section{Materials and methods}

\section{Selection and preparation of samples}

Faecal samples were taken at random from those submitted to Sheffield Public Health Laboratory (PHL) during 1987 from patients with acute diarrhoea of presumed infectious origin. Samples of reservoir water and the intestinal contents of brown trout (Salmo trutta) were collected by Sheffield Environmental Health Department (EHD) during investigation of a possible

Received 6 Nov. 1989; accepted 15 Jan. 1990 outbreak of waterborne cryptosporidiosis in Sheffield. ${ }^{14}$ Cattle faeces were collected randomly from an abattoir by Sheffield EHD during another investigation. ${ }^{17}$ Samples of water and filter-sand from a swimming pool were collected by Doncaster EHD and Sheffield EHD during investigation of an outbreak of cryptosporidiosis associated with a swimming pool in Doncaster (Dr P. Fenton, personal communication).

For faeces or intestinal contents, a suspension (c. $25 \% \mathrm{v} / \mathrm{v}$ ) was made in phosphate-buffered saline $\mathrm{pH} 7 \cdot 2$ (PBS). This was tested by EIA as a crude suspension, and also as a supernate after centrifugation at $3000 \mathrm{~g}$ at $4^{\circ} \mathrm{C}$ for $20 \mathrm{~min}$.

Water samples $(20 \mathrm{~L})$ were filtered through a $0.45-\mu \mathrm{m}$ membrane filter (Pall Process Filtration Ltd). The membranes were then cut into small pieces and agitated in $100 \mathrm{ml}$ of PBS with Tween $200.1 \% \mathrm{v} / \mathrm{v}$, to release any deposit. The resulting suspension was centrifuged at $3000 \mathrm{~g}$ at $4^{\circ} \mathrm{C}$ for $20 \mathrm{~min}$, and the deposit was resuspended in $200 \mu \mathrm{l}$ of PBS and used directly in the EIA.

Sand samples $(100 \mathrm{~g})$ were added to $100 \mathrm{ml}$ of PBS with Tween $201 \% \mathrm{v} / \mathrm{v}$ in a plastic jar, and shaken vigorously for $5 \mathrm{~min}$. The sand was allowed to settle for $5 \mathrm{~min}$ and the supernate was then removed and centrifuged at $3000 \mathrm{~g}$ at $4^{\circ} \mathrm{C}$ for $20 \mathrm{~min}$. The supernate was discarded and the deposit was resuspended in $1 \mathrm{ml}$ of PBS.

Microscopic examination on all samples, and EIA on human faecal samples, were performed within $24 \mathrm{~h}$ of receipt. Other samples were stored at $4^{\circ} \mathrm{C}$ for up to 1 month before examination by EIA.

\section{Microscopy}

Samples were examined by a modified Ziehl-Neelsen (ZN) method ${ }^{18}$ and those containing bodies resembling cryptosporidium oocysts were tested by a direct immunofluorescence (IF) method with a mouse IgM MAb 
conjugated to fluorescein isothiocyanate (FITC) ${ }^{19}$ The reagents were supplied by the Division of Microbiological Reagents and Quality Control (DMRQC).

\section{Enzyme immunoassay (EIA)}

Monoclonal antibodies and conjugates. A mouse MAb to cryptosporidium oocysts (MAb-Cl), and MAb-C1 conjugated to FITC, have been described by McLauchlin et al. ${ }^{19} \mathrm{~A}$ MAb to FITC described by Samuel et al. ${ }^{20}$ has been conjugated with horseradish peroxidase (EC 1.11.1.7) by Wilson and Nakane. ${ }^{21}$ For the present study, these antibodies and conjugates were prepared at the DMRQC and were used at their optimal dilutions.

Coating of EIA plates. Polystyrene 96-well EIA plates (Costar, Northumbria Biologicals) were coated with unconjugated MAb-Cl (whole ascitic fluid): $100 \mu$ l of the MAb-Cl diluted in PBS was placed in each well and the plate was shaken at ambient temperature for $10 \mathrm{~min}$. After refrigeration overnight, plates were washed three times with PBS containing Tween $200.5 \% \mathrm{v} / \mathrm{v}$. Any uncoated sites were blocked by adding $100 \mu \mathrm{l}$ of blanking reagent (RPMI 1640 medium [Flow Laboratories] with fetal bovine serum $10 \% \mathrm{v} / \mathrm{v}$ and bovine serum albumin $1 \% \mathrm{v} / \mathrm{v})$, shaking, and incubating at $37^{\circ} \mathrm{C}$ for $1 \mathrm{~h}$. Blanking reagent was then discarded and the plates were washed three times as above. If they were not used immediately, they were stored in a heat-sealed polythene bag at $-20^{\circ} \mathrm{C}$ for up to 1 month, and were then allowed to reach ambient temperature before use.

EIA test procedure. On each plate were included a faecal sample known to contain cryptosporidium oocysts and a negative control sample (washing buffer alone). For the test, $50 \mu \mathrm{l}$ of sample was added to each of two wells, and the plates were shaken at ambient temperature for $90 \mathrm{~min}$ and washed three times as above; $100 \mu \mathrm{l}$ of MAb-Cl conjugated with FITC, diluted in blanking reagent, was then added to each well. After shaking at ambient temperature for a further $90 \mathrm{~min}$, plates were washed three times as above; $100 \mu \mathrm{l}$ of anti-FITC conjugated with horseradish peroxidase, diluted in blanking reagent, was then added to each well and the plate was shaken and washed as above. Freshly prepared substrate solution (chromogenic substrate $3: 3^{\prime} 5,5^{\prime}$ tetramethylbenzidine dissolved in dimethyl sulphoxide) was diluted for use in citrate acetate buffer as described by Bos et al. $;^{22} 100 \mu \mathrm{l}$ was added to each well, and the plate was shaken at ambient temperature for $10 \mathrm{~min}$. The colour reaction was stopped by adding $50 \mu \mathrm{l}$ of sulphuric acid $3 \%$ to each well, and the results were then read within $1 \mathrm{~h}$. Optical density (OD) at $450 \mathrm{~nm}$ was read against an untreated well containing $150 \mu \mathrm{l}$ of PBS as zero. Results were recorded as positive if the mean of the OD values for the two wells of the sample exceeded the mean +3 SD of the OD values for the two wells of the negative control.

\section{Further tests on EIA-positive microscopy-negative specimens}

Faecal samples that gave positive results by EIA but negative results by microscopy were, where possible, investigated further as follows: (1) concentration by a formalin-ether procedure ${ }^{23}$ and re-testing by modified $\mathrm{ZN}$ and IF techniques; (2) examination for rheumatoid factor with a latex kit (Rheuma-Wellcotest, Wellcome Diagnostics); (3) examination for salmonellae, shigellae, campylobacters, parasites, and pathogenic Escherichia coli by methods described previously, ${ }^{17,24}$ and examination for viruses by a rotavirus EIA (DMRQC) and electronmicroscopy; (4) examination by EIA with other mouse MAbs (DMRQC) raised against Bartonella bacilliformis, Listeria monocytogenes, and Legionella pneumophila.

\section{Titration of EIA-pasitive specimens and an oocyst suspension}

Cryptosporidium oocysts were purified from a positive human faecal sample by sucrose flotation concentration ${ }^{25}$ followed by Percoll (Pharmacia/LKB) discontinuous density gradient centrifugation. ${ }^{26}$ Purified oocysts were then washed three times in PBS and resuspended to give a concentration of $c .10^{6}$ oocysts $/ \mathrm{ml}$. Purified oocyst suspension, faecal samples that gave positive results by both EIA and microscopy, and faecal samples that were EIA-positive and microscopy-negative, were then diluted serially to 1 in 64 in liquid faeces that gave negative results by both EIA and microscopy. Each dilution was tested in triplicate by the cryptosporidium EIA, and the mean OD was plotted against the dilution.

\section{Results}

The results of initial EIA and microscopic examination for Cryptosporidium are summarised in table I. Of 494 human faecal samples examined, $17(3 \%)$ gave positive results by both microscopy and EIA, $28(6 \%)$ were positive by EIA but negative by microscopy, and $1(0.2 \%)$ was positive by microscopy but negative by EIA. Of 81 environmental samples examined, 30 (37\%) gave positive results by both microscopy and EIA, $11(14 \%)$ were positive by EIA but negative by microscopy, and 5 (6\%) were positive by microscopy but negative by EIA. All samples that gave positive results when stained by a modified $\mathrm{ZN}$ method also gave positive results by IF. No differences in reactivity in EIA were observed between tests with faecal suspensions and faecal supernates.

The results of some further examinations on specimens which were positive by EIA but negative by microscopy are shown in table II. All 28 samples examined gave negative results by microscopy for cryptosporidium oocysts after concentration. Five of 28 contained other recognised intestinal pathogens (Campylobacter jejuni 3, Salmonella enteritidis 1, and rotavirus 1). All 19 samples tested gave negative results for rheumatoid factor. Of nine 
Table I. Detection of Cryptosporidium by microscopy and EIA

\begin{tabular}{lcccc}
\hline & \multicolumn{3}{c}{ Number of specimens that were positive by } \\
\cline { 2 - 5 } \multicolumn{1}{c}{$\begin{array}{c}\text { Type of specimen } \\
\text { (number examined) }\end{array}$} & $\begin{array}{c}\text { both } \\
\text { microscopy } \\
\text { and EIA }\end{array}$ & $\begin{array}{c}\text { microscopy } \\
\text { alone }\end{array}$ & $\begin{array}{c}\text { EIA } \\
\text { alone }\end{array}$ & $\begin{array}{c}\text { neither } \\
\text { microscopy } \\
\text { nor EIA }\end{array}$ \\
\hline Human faeces (494) & 17 & 1 & 28 & 448 \\
Surface water (14) & 10 & 0 & 4 & 0 \\
Treated drinking water (2) & 0 & 0 & 0 & 2 \\
Cattle faeces (12) & 9 & 3 & 0 & 0 \\
Brown trout (18) & 7 & 2 & 5 & 4 \\
Swimming pool water (32) & 3 & 0 & 0 & 29 \\
Filter-sand (3) & 1 & 0 & 2 & 0 \\
& & & &
\end{tabular}

samples examined in other EIA systems, nine gave positive results with MAb to $B$. bacilliformis, nine and seven gave positive results with two different MAbs to List. monocytogenes and eight gave positive results with MAb to Legion. pneumophila.

The results of the titrations are shown in the figure. Curves obtained with purified oocysts, and with faecal samples that gave positive results by both microscopy and EIA, are similar and show a steady decrease in OD with dilution of the specimen. With faecal samples that were positive by EIA but negative by microscopy, there was no such simple relationship between the $O D$ and the dilution of the specimen.

\section{Discussion}

The laboratory diagnosis of cryptosporidiosis, as with other protozoal diarrhoeal diseases, presently relies on the recognition by conventional light microscopy of morphological features specific to the parasite. Unfortunately these techniques may be laborious, insensitive, and prone to error with inexperienced staff. ${ }^{27,28}$ Staining procedures for

Table II. Further tests on 28 faecal samples that were positive for Cryptosporidium by EIA but negative by direct microscopy

\begin{tabular}{lcc}
\hline & \multicolumn{2}{c}{ Number of specimens } \\
\cline { 2 - 3 } \multicolumn{1}{c}{ Further test } & tested & positive \\
\hline Concentration and microscopy & 28 & 0 \\
Examination for other pathogens & 28 & 5 \\
Examination for rheumatoid factor & 19 & 0 \\
EIA for B. bacilliformis & 9 & 9 \\
EIA for List. monocytogenes & 9 & 9 \\
EIA for Legion. pneumophila & 9 & 8 \\
& & \\
\hline
\end{tabular}

oocysts of Cryptosporidium have been reviewed by Garza et al..$^{29}$ and Casemore et al..$^{23}$ and difficulties in distinguishing cryptosporidium oocysts from non-cryptosporidial bodies have been reported. ${ }^{29,30}$ Immunofluorescent microscopy based upon fluorescein-labelled MAb to cryptosporidium oocysts has been described $;^{19,31}$ this indicated the

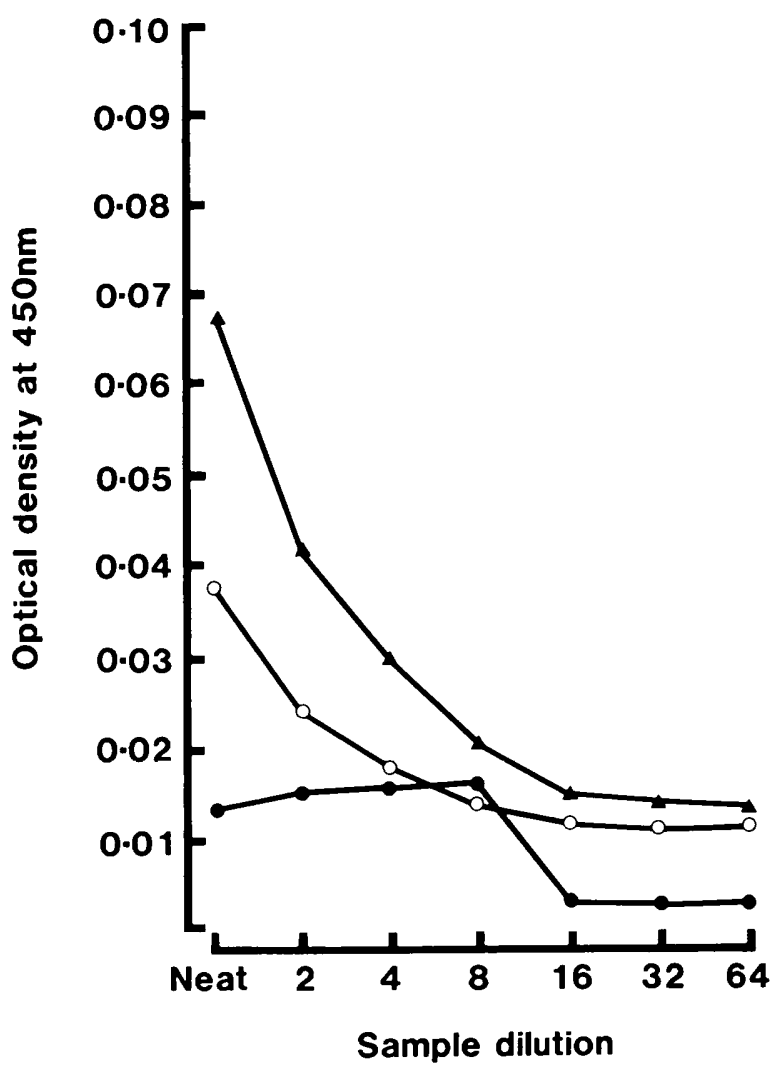

Figure. Titration, by EIA for Cryptosporidium, of a suspension of purified oocysts $(O)$, and of faecal samples that were EIApositive but by microscopy were either positive $(\boldsymbol{A})$ or negative (O). Each point represents the mean of three assays. 
presence of occysts in human and animal faeces, but did not include detection of cryptosporidium oocysts in environmental samples.

Confirmation of the presence of Cryptosporidium in environmental samples is laborious and costly ${ }^{32}$ and is often difficult because oocysts from such samples may stain atypically in conventional and IF techniques. ${ }^{16,33}$ Separation of oocysts from other particulate material in water, to permit microscopy, may require sequences of filtration, chemical treatment, flotation and density gradient centrifugation. ${ }^{16,32-35}$ According to Ongerth and Stibbs, ${ }^{16}$ microscopic examination of the material collected from $20 \mathrm{~L}$ of water may take up to $6 \mathrm{~h}$. It is possible that waterborne spread of Cryptosporidium may be suspected more often in future, and the ability to detect this parasite in drinking water supplies will be a serious problem with present detection methods. ${ }^{32,35}$

In a review of parasite-related diarrhoeas, the World Health Organization ${ }^{36}$ advocated the development of methods less subjective than microscopy for detecting protozoa and their cysts. Early enzyme immunoassays to detect cysts ${ }^{37,38}$ were based on polyclonal antibodies and were of unacceptably low sensitivity. Other assays ${ }^{39}$ based on MAbs appeared to offer improved sensitivity and specificity.

We describe here an EIA based on a MAb to Cryptosporidium (MAb-C1) for detecting the organism in faecal and environmental samples. The assay gave positive results with both faecal suspensions and faecal supernates, suggesting that the antigen detected may be either soluble or particulate. It also gave positive results when cysts were not recognisable by microscopy, possibly because they had disintegrated. This assay is as sensitive as, but less subjective than, microscopic examination

\section{REFERENCES}

1. Chapman PA. Cryptosporidiosis: recent trends in epidemiology, diagnosis and treatment. Serodiagn Immunother Infect Dis 1988; 2: 311-317.

2. Pohlenz J, Moon HW, Cheville NF, Bemrick WJ. Cryptosporidiosis as a probable factor in neonatal diarrhoea of calves. J Am Vet Med Assoc 1978; 172 : 452-457.

3. Tzipori S. Cryptosporidiosis in animals and humans. Microbiol Rev 1983; 47: 84-96.

4. Bennett M, Baxby D, Blundell N, Gaskell CJ, Hart CA, Kelly DF. Cryptosporidiosis in the domestic cat. Vet Rec 1985; 116: 73-74.

5. Anderson BC, Hall RF. Cryptosporidial infection in Idaho dairy calves. J Am Vet Med Assoc 1982; 181 ; 484-485.

6. Reese NC, Current WL, Ernst JV, Bailey WS. Cryptosporidiosis of man and calf: a case report and results of experimental infections in mice and rats. Am J Trop Med Hyg 1982; 31 : 226-229. of stained smears. However, the assay did produce a positive result in $28(6 \%)$ of 476 faecal specimens that gave negative results by microscopy. Microscopy of all 28 samples remained negative after concentration; others ${ }^{40}$ have reported that such concentration techniques offer little increase in diagnostic efficiency. It is possible that the EIA may offer a genuine increase in sensitivity compared with microscopy. However, the observed parallel between titration curves of EIA-positive microscopy-positive samples and purified oocysts, and the lack of parallel between either of these curves and that obtained with EIA-positive microscopynegative samples suggests that something other than cryptosporidium oocysts was causing positive EIA results in the latter. ${ }^{41,42}$ This may be soluble antigen(s) or other stages in the life cycle of Cryptosporidium, or merely a non-specific background effect. Rheumatoid factor, which may be present in body fluids during inflammation and which is a common cause of false positive EIA results, ${ }^{43,44}$ was not detected in 19 samples examined with a latex kit. The finding that many of the EIA-positive microscopy-negative specimens reacted in other EIA systems with MAbs raised against unrelated organisms suggests that these may be false positive results. Although potentially useful as a screening test, further development and refinement of the method is required before it could replace microscopy in the diagnosis of cryptosporidiosis.

We thank D. Smith and S. King of Yorkshire Water Authority, and the staff of Sheffield PHL, Sheffield EHD and Doncaster EHD for their help in this study, and Professor B. I. Duerden, Sheffield University Medical School, for helpful advice during the preparation of this manuscript.

7. Casemore DP, Jessop EG, Douce D, Jackson FB. Cryptosporidium plus Campylobacter: an outbreak in a semirural population. J Hyg (Lond) 1986; 96: 95-105.

8. Baxby D, Hart CA, Taylor C. Human cryptosporidiosis: a possible case of hospital cross infection. Br Med J 1983; 287: $1760-1761$

9. Soave R, Danner RL, Honig CL et al. Cryptosporidiosis in homosexual men. Ann Intern Med 1984; 100 : 504-511.

10. Koch KL, Phillips DJ, Aber RC, Current WL. Cryptosporidiosis in hospital personnel: evidence for person-toperson transmission. Ann Intern Med 1985; 102: 593596.

11. Weber J. Sexually acquired parasitic infections in homosexual men. Parasitol Today 1985; 1: 93-95.

12. D'Antonio RG, Winn RE, Taylor JP et al. A waterborne outbreak of cryptosporidiosis in normal hosts. Ann Intern Med 1985; 103: 886-888.

13. Isaac-Renton JL, Fogel D, Stibbs HH, Ongerth JE. Giardia and Cryptosporidium in drinking water. Lancet 1987; 1 : 973-974. 
14. Rush BA, Chapman PA, Ineson RW. A probable waterborne outbreak of cryptosporidiosis in the Sheffield area. J Med Microbiol 32: 239-242.

15. Smith HV, Girdwood RWA, Patterson WJ et al. Waterborne outbreak of cryptosporidiosis. Lancet 1988; 2 : 1484.

16. Ongerth JE, Stibbs HH. Identification of Cryptosporidium oocysts in river water. Appl Environ Microbiol 1987; 53: 672-676.

17. Chapman PA, Wright DJ, Norman P. Verotoxin-producing Escherichia coli infections in Sheffield: cattle as a possible source. Epidemiol Infect 1989; 102: 439-445.

18. Garcia LS, Bruckner DA, Brewer TC, Shimizu RY. Techniques for the recovery and identification of Cryptosporidium oocysts from stool specimens. J Clin Microbiol 1983; 18: 185-190.

19. McLauchlin J, Casemore DP, Harrison TG, Gerson PJ, Samuel D, Taylor AG. Identification of Cryptosporidium oocysts by monoclonal antibody. Lancet $1987 ; 1: 51$.

20. Samuel D, Patt RJ, Abuknesha RA. A sensitive method of detecting proteins on dot and western blots using a monoclonal antibody to FITC. J Immunol Methods $1988 ; 107: 217-224$.

21. Wilson MB, Nakane PK. Recent developments in the periodate method of conjugating horseradish peroxidase (HRPO) to antibodies. In: Knapp W, Holubar K, Wick $\mathrm{G}$ (eds) Immunofluorescence and related staining techniques. Amsterdam, Elsevier. 1978: 215-224.

22. Bos ES, van der Doelen AA, van Rooy N, Schuurs AHWM. 3,3'5,5'-tetramethylbenzidine as an Ames test negative chromogen for horse-radish peroxidase in enzyme immunoassay. J Immunoassay 1981; 2 : 187-204.

23. Casemore DP, Armstrong $M$, Sands RL. Laboratory diagnosis of cryptosporidiosis. J Clin Pathol 1985; 38: 1337-1341.

24. Chapman PA, Mitchelmore DL. A two-year survey of the incidence of heat-labile enterotoxin-producing Escherichia coli and other enteric pathogens in travellers returning to the Sheffield area. Epidemiol Infect 1988; 101 : 239-247.

25. Sheather AL. The detection of intestinal protozoa and mange parasites by a flotation technique. J Comp Pathol 1923; 36: 266-275.

26. Waldman E, Tzipori S, Forsyth JR. Separation of Cryptosporidium species oocysts from feces using a Percoll discontinuous density gradient. J Clin Microbiol 1986; 23: 199-200.

27. Healy GR. Laboratory diagnosis of amoebiasis. Bull $N Y$ Acad Med 1971; 47: 478-493.

28. Krogstad DJ, Spencer HC, Healy GR, Gleason NN, Sexton DJ, Herron CA. Amoebiasis: epidemiologic studies in the United States, 1971-1974. Ann Intern Med 1978; 88: 89-97.
29. Garza D, Hopfer RL, Eichelberger C, Eisenbach S, Fainstein V. Fecal staining methods for screening Cryptosporidium oocysts. J Med Technol 1984; 1 : 560563.

30. Ma P, Soave R. Three-step stool examination for cryptosporidiosis in 10 homosexual men with protracted watery diarrhea. $J$ Infect Dis $1983 ; 147: 824-828$.

31. Sterling CR, Arrowood MJ. Detection of Cryptosporidium sp. infections using a direct immunofluorescent assay. Pediatr Infect Dis J 1986; 5: s139-s142.

32. Logsdon GS. Cryptosporidium. J Am Water Workers Assoc $1988 ; 80$ (No. 2): 14-27.

33. Musial CE, Arrowood MJ, Sterling CR, Gerba CP. Detection of Cryptosporidium in water using polypropylene cartridge filters. Appl Environ Microbiol 1987; 53: 687-692.

34. Rose JB, Cifrino A, Madore MS, Gerba CP, Sterling CR, Arrowood MJ. Detection of Cryptosporidium from waste-water and fresh-water environments. Water Sci Technol 1986; 18: 233-239.

35. Rose JB. Occurrence and significance of Cryptosporidium in water. J Am Water Workers Assoc 1988; 80 : 53-58.

36. World Health Organization. Parasite related diarrhoeas. Bull WHO 1980; 58: 819-830.

37. Ungar BLP, Yolken RH, Nash TE, Quinn TC. Enzymelinked immunosorbent assay for the detection of Giardia lamblia in fecal specimens. J Infect Dis 1984; 149: 9097.

38. Yolken RH, Ungar B. ELISA detection of Giardia lamblia. Lancet 1985; $2: 1120$.

39. Ungar BLP, Yolken RH, Quinn TC. Use of monoclonal antibody in an enzyme immunoassay for the detection of Entamoeba histolytica in fecal specimens. Am J Trop Med 1985; 34: 465-472.

40. McNabb SJN, Hensel DM, Welch DF, Heijbel H, McKee GL, Istre GR. Comparison of sedimentation and flotation techniques for identification of Cryptosporidium sp. oocysts in a large outbreak of human diarrhea. $J$ Clin Microbiol 1985; 22 : 587-589.

41. Perlstein MT, Chan DW, Bill MJ. Parallelism: a useful tool for troubleshooting. J Clin Immunoassay 1980; 3: 3436.

42. Hamilton RG, Adkinson NF. Quantitative aspects of solid phase immunoassays. In: Kemeny DM, Challacombe S (eds) ELISA and other solid phase immunoassays. Chichester, John Wiley. 1988: 57-84.

43. Yolken RH, Stopa PJ. Analysis of nonspecific reactions in enzyme-linked immunosorbent assay testing for human rotavirus. J Clin Microbiol 1979; 10: 703-707.

44. Tijssen P. Practice and theory of enzyme immunoassays. (Laboratory techniques in biochemistry and molecular biology 15). Amsterdam, Elsevier. 1985: 374-375. 
